\title{
Promoting justice by treating people unequally: an experimental study
}

\author{
Alice Becker • Luis M. Miller
}

Received: 28 January 2009 / Accepted: 7 August 2009 / Published online: 25 August 2009

(c) The Author(s) 2009. This article is published with open access at Springerlink.com

\begin{abstract}
Which inequalities among individuals are considered unjust? This paper reports the results of an experiment designed to study distributive choices dealing with arbitrarily unequal initial endowments. In a three-person distribution problem where subjects either know or do not know their endowments, we find impartial behavior to be a stable pattern. Subjects either compensate for initial inequalities fully or not at all in both conditions, and they do so more often when they do not know their endowment than when they know it. Moreover, the type and the size of the good to be distributed also affect the frequency of impartial behavior.
\end{abstract}

Keywords Veil of ignorance - Impartial behavior - Distributive justice · Procedural fairness

JEL Classification $\mathrm{C} 72 \cdot \mathrm{C} 92$

\section{Introduction}

The experimental analysis of justice theories in the last two decades (Konow 2003) has predominantly focused on merit and entitlement arguments, but has not paid

Electronic supplementary material The online version of this article

(http://dx.doi.org/10.1007/s10683-009-9222-z) contains supplementary material, which is available to authorized users.

\footnotetext{
A. Becker

Max Planck Institute of Economics, Kahlaische Straße 10, 07745 Jena, Germany

e-mail: becker@econ.mpg.de

L.M. Miller $(\bowtie)$

Centre for Experimental Social Sciences, Nuffield College, University of Oxford, New Road, OX1 1NF, Oxford, UK

e-mail: luis.miller@nuffield.ox.ac.uk
} 
much attention to the role played by arbitrariness in justice judgments. Questions related to whether people actually compensate arbitrary inequalities when they have the opportunity to do so, and, more specifically, which principles they use to eliminate those inequalities, have hardly been explored. This is so even when considering that principles of redress and compensation for undeserved inequalities are the foundation of important public intervention schemes such as affirmative action and positive discrimination policies. Empirical studies may contribute to this debate by helping to understand the normative principles these policies rely on.

This paper reports the results of an experiment designed to study distributive choices dealing with arbitrarily unequal initial endowments. More specifically, we are interested in how choices depend on endowments given different situations, where participants either know their own endowment or only the distribution of endowments. Previous experimental literature on distributive justice has found a fair amount of egalitarian behavior, especially when initial endowment is just manna from heaven (see Camerer 2003 for an overview). Only recently have a number of experimental papers studied merit-based initial inequalities, finding that merit and entitlement arguments considerably reduce egalitarianism. When participants bargain over money that was earned in a preceding production phase, they are willing to accept unequal distributions (Rutström and Williams 2000; Cherry et al. 2002). Some studies also combine this production phase with an arbitrary element, i.e., a random rate of return (Cappelen et al. 2007). Both types of studies find similar results: very little redistribution takes place. However, none of these studies attempts to isolate the effect of arbitrariness in initial inequalities.

To address this issue, we conduct a simple experiment where participants arbitrarily differ in their initial endowments and decide how to allocate an additional pie among a group of three individuals (including themselves). Since we are interested in the governing principle of distributive justice that individuals follow in such a specific unequal situation, we compare behavior behind a veil of ignorance and when this veil is lifted (Rawls 1971). We implement the veil of ignorance via a random dictatorship mechanism, i.e. every member of the society states one allocation for all its members, where one of those allocations is chosen randomly and implemented.

Moreover, we account for the fact that, besides the allocation itself, it may play a role for individuals how this allocation is achieved. This issue becomes particularly crucial when, for instance, a good is indivisible, such as a house or a piece of art. If in this case, furthermore, no compensation is possible, a fair outcome in distributional terms is necessarily ruled out (Young 1994). Nevertheless, the outcome can be perceived as fair when it was achieved following a fair procedure. Compared to a fair allocation, which implies an ex-post equality of outcomes, a fair procedure refers to an ex-ante equality of opportunities, where everyone is equally likely to get the (indivisible) good ex post. Recent studies have shown that individuals are indeed sensitive to procedures. Bolton et al. (2005) find that the feasibility of a fair allocation and a fair procedure affect rejection behavior in simple bargaining problems in a similar way. Moreover, Karni et al. (2008) find that many subjects are willing to give up part of their own winning probability in order to achieve a fairer procedure overall. To be able to study the effect of fair procedures vs. fair allocations on justice judgments, we distinguish between the distribution of a divisible and an indivisible good. 
The rest of the paper proceeds as follows. Section 2 describes the experimental design and procedure. Section 3 derives some predictions. Section 4 presents the main results of the experiment. Section 5 discusses the results and concludes.

\section{Design}

We study a three-person one-shot pure distribution problem. In the beginning of the experiment subjects are randomly matched in groups of three. Each group member $i$ receives a different identity that corresponds to an initial endowment $e_{i}$ where $i \in$ $\{A, B, C\}$. These initial endowments differ, such that $\left(e_{B}-e_{A}\right)=\left(e_{C}-e_{B}\right)$.

Additionally, each group receives a pie $P$, and subjects decide how to allocate this additional pie among the three group members. Thus, every group member $i$ states three shares, one for each group member. All shares stated by all group members are given by matrix $S=\left(s_{i j}\right)_{i, j=A, B, C}$, where every row represents the decisions made by one group member

$$
\mathbf{S}=\left(\begin{array}{lll}
s_{A A} & s_{A B} & s_{A C} \\
s_{B A} & s_{B B} & s_{B C} \\
s_{C A} & s_{C B} & s_{C C}
\end{array}\right) .
$$

Furthermore, all allocations of the additional pie are efficient, i.e. $\forall i: \sum_{j=A, B, C} s_{i j}=$ $P$. The actual distribution of the additional pie $\mathbf{s}_{\mathbf{i}}=\left(s_{i A}, s_{i B}, s_{i C}\right)$ is chosen via random dictatorship mechanism.

Following this basic structure, we manipulate two treatment variables. First, whereas the set of initial endowments is common knowledge in all treatments, in only one half of the treatments subjects learn their own initial endowment, i.e. their identity, before they decide on the allocation of the additional pie. In the other half of the treatments, subjects do not learn their initial endowment beforehand. Hence they make their decision behind a veil of ignorance. We refer to this first treatment variable as 'Information about identity'. Note that in our implementation of the veil of ignorance the random dictator holds a personal stake in the allocation she states (see Frohlich et al. 2004). Other approaches make use of impartial spectators who are not stakeholders (Konow 2000). Konow argues that a decision made behind the veil of ignorance, where the dictator is a stakeholder, could be affected by the dictator's risk attitude. Implementing the veil of ignorance like we did renders it optimal to state one's economically preferred allocation.

Second, the initial endowments and the additional pie are given in experimental currency units (ECU) in only half of the treatments. In the other half they are given in lottery tickets. In the first case, the payoff for each subject amounts to $\pi_{i}=e_{i}+s_{i i}, \forall i \in\{A, B, C\}$. In the latter case, the number of lottery tickets held by each subject represents the probability of winning a prize. The size of the initial endowments and the pie are thereby equal in both cases, only that they are denoted ECU in the first case and lottery tickets in the second. After distributing the pie in each group in the second case, one independent lottery per group is conducted, in which one of the three group member wins the prize. The prize is comprised of an 
Table 1 Experimental design

\begin{tabular}{|c|c|c|c|c|c|}
\hline Treatment & Obs. & Initial endowments & $\begin{array}{l}\text { Additional } \\
\text { pie }\end{array}$ & $\begin{array}{l}\text { Information } \\
\text { about identity }\end{array}$ & Type of good \\
\hline$T^{00}$ & 30 & $e_{i} \in\{20,40,60\}$ & $P=60$ & no & indivisible \\
\hline$T^{10}$ & 30 & & & & divisible \\
\hline$T^{01}$ & 30 & & & yes & indivisible \\
\hline$T^{11}$ & 30 & & & & divisible \\
\hline$T^{00}$ & 30 & $e_{i} \in\{20,40,60\}$ & $P=180$ & no & indivisible \\
\hline$T^{10}$ & 30 & & & & divisible \\
\hline$T^{01}$ & 30 & & & yes & indivisible \\
\hline$T^{11}$ & 30 & & & & divisible \\
\hline$T^{10}$ (asymm. 1) & 30 & $e_{i} \in\{16,48,56\}$ & $P=180$ & no & divisible \\
\hline$T^{10}$ (asymm. 2) & 30 & $e_{i} \in\{24,32,64\}$ & & & \\
\hline
\end{tabular}

amount of ECU equal to the sum of payoffs in the other condition. We call this second treatment variable 'Type of good'. The provision of endowments and the pie in monetary terms reflects the distribution of a good that is divisible. Given in probabilities they represent the decision over a procedure on how to distribute an indivisible good. It should be emphasized that the probability of winning the indivisible good is linearly increasing in the amount of lottery tickets a subject possesses.

The manipulation of our two treatment variables leads to a $2 \times 2$ factorial design, which was conducted in four sessions, one session for each treatment. The different treatments are denoted by $T^{d k}$, where $d=1$ if the good is divisible, 0 otherwise, and $k=1$ if the identity is known, 0 otherwise. The decisions made in each treatment will be denoted by the different matrices $\mathbf{S}^{d k}$. The set of initial endowments and the additional pie are given by $e_{i} \in\{20,40,60\}$ and $P=60$ ECU or lottery tickets. Thus, the lottery prize (the indivisible good) amounts to $180 \mathrm{ECU}$ and each lottery ticket represents a $1 / 180$ probability of winning.

In order to check the robustness of the results found in the first four treatments, we ran six extra sessions with different variations. First, we increased the size of the additional pie to $P=180$. Second, we changed the initial inequalities between the identities, that were symmetric before, such that $\left(e_{B}-e_{A}\right)=4\left(e_{C}-e_{B}\right)$ (denoted by 'asymm. 1'), and $\left(e_{B}-e_{A}\right)=\frac{\left(e_{C}-e_{B}\right)}{4}$ (denoted by 'asymm. 2'). Whereas the first variation was run for all four original treatments, we conducted the second variation only for treatment $T^{10}$ and a pie size of $P=180$. We ran these six additional sessions under the same conditions as the previous four, with the only difference being that we changed the exchange rate to $100 \mathrm{ECU}=6$ euros, in order to keep the monetary incentives constant. Our experimental design is summarized in Table 1.

The computerized experiment was conducted at the laboratory of the Max Planck Institute of Economics in Jena, using the z-Tree software (Fischbacher 2007). The participants in the experiment were undergraduate students from different disciplines at the University of Jena who were recruited using ORSEE (Greiner 2004). None of the participants was informed of the purpose of the experiment and subjects were 
allowed to participate only once. After being seated at separate computer terminals, the subjects received written instructions, which were also read aloud by the experimenter to ensure that they had understood the instructions. ${ }^{1}$ The experiment started with a control questionnaire, which the subjects had to complete to assure the understanding of the instructions. Questions were answered privately. We ran ten sessions, one session per treatment, with each session involving 30 participants and lasting on average 50 minutes. The subjects earned experimental currency units (ECU) during the sessions, which were afterwards transformed into euros at an exchange rate of $100 \mathrm{ECU}=10$ euros (100 ECU $=6$ euros, in the robustness checks sessions). The average earnings per subject were 9.57 euros and ranged from a minimum of 3.50 euros to a maximum of 21.00 euros, including the show-up fee of 2.50 euros.

\section{Predictions}

First, we consider a risk neutral selfish player $i$, i.e. an expected value maximizer.

Without information about their own identity players obtain the different identities $A, B$ and $C$ each with a probability of one third. Player $i$ 's choice is implemented with a probability of one third, i.e. each single element of matrix $\mathbf{S}$ above will be realized for player $i$ with a probability of one ninth. As all allocations of the pie are efficient, the expected value of the pie share that is realized for group member $i$ is constant, i.e. $\frac{P}{3}$. As a result, when identities are unknown choice does not matter for the risk neutral selfish player, since any choice maximizes her expected value. When a subject knows her identity, only three out of nine elements of matrix $\mathbf{S}$ are relevant for her payoff, each of which will be realized with a probability of one third due to the random dictator mechanism. As only one of those three relevant elements can be influenced by subject $i$, a selfish subject would allocate the whole pie to herself.

As pointed out in Sect. 2, we introduce the distinction between the divisible and the indivisible good via a final lottery after the additional pie is distributed. This lottery allocates a prize to one of the group members, with probabilities according to the relative number of lottery tickets gained in the indivisible good treatment. The prize is equal to the sum of subjects' gains in the divisible good treatment. Therefore, from an expected value maximizing risk neutral perspective, the type of good manipulation should not affect behavior.

Second, we derive predictions for a subject $i$ endowed with other-regarding preferences.

If we find a behavioral pattern when information about the identities is provided, one could argue this is due to the social concern of subject $i$. A model of inequality aversion (e.g. Fehr and Schmidt 1999 or Bolton and Ockenfels 2000) would predict that subjects distribute the additional pie, s.th. final outcomes are equal. A subject that

\footnotetext{
${ }^{1}$ Instructions (translation into English) and raw experimental data are available on the Journal web page as Supplementary Material.
} 
has such preferences would take into account initial inequalities without information about identities as well as when identities are known. ${ }^{2}$

A consideration of personal sentiments, like envy (see e.g. Beckman et al. 2002), would reflect behavioral differences depending on the initial endowment $(A, B, C)$ with information about identities.

As long as the subject $i$ is risk neutral the type of good manipulation should not affect behavior. Note that we incorporate the indivisible good by using the so-called lottery-points method, introduced by Roth and Malouf (1979) (see also Berg et al. 1986; Cox et al. 1982). Under the assumption that EUT applies, this procedure induces risk neutrality concerning that additional lottery. Thus, behavior in the divisible vs. indivisible good condition should not differ, even if the subject is risk averse in general. $^{3}$

We now use the previous literature on the multiplicity of fairness rules to sharpen our predictions (see Frohlich and Oppenheimer 1992; Konow 2000; Frohlich et al. 2004; Cappelen et al. 2007). In line with our first assumption, a significant proportion of subjects behaving in a self-interested manner is always found. However, other-regarding behavior still exists, not only when an impartial mechanism is implemented, but also when participants can condition on their role in the game. This literature also finds other-regarding behavior to be heterogeneous. ${ }^{4} \mathrm{~A}$ wellknown example of socially oriented behavior is 'egalitarianism' or 'strict egalitarianism' (Frohlich et al. 2004; Cappelen et al. 2007). Egalitarians would divide the pie equally regardless of the initial endowments. In studies that introduce a production phase before the distribution task, a second category of other-regarding behavior emerges. Scholars refer to this second category as 'just deserts' (Cherry et al. 2002; Frohlich et al. 2004) or 'liberal egalitarianism' (Cappelen et al. 2007), and it implies adopting a rule that allocates the final amount of money proportionally to each participant's contribution or effort in the production phase. Our design does not involve a production phase and initial endowments are assigned purely random. However, a proportional rule is still possible. The proportional rule would imply that subjects take into account inequalities and compensate for them because they think they are unfair; especially because those inequalities are arbitrary and not deserved in our case. A full compensation of initial arbitrary inequalities has been mentioned in connection with the veil of ignorance as the principle of redress. ${ }^{5}$

\footnotetext{
${ }^{2}$ If the subject is risk averse, behavioral predictions when identities are unknown coincide with the predictions above (we will further account for that aspect in the discussion). However, this does not hold for behavior when identities are known.

${ }^{3}$ However, if EUT is violated, e.g. due to a limited computing capacities of the subjects, or the procedure we use just does not work, the predictions somewhat differ. When identities are known a risk averse subject would allocate more lottery tickets to herself in the indivisible good treatment than she would allocate ECU to herself in the divisible good treatment. Without information about identities predictions for the risk averse subject and the subjects with other-regarding preferences again coincide.

${ }^{4}$ For heterogeneous social preferences in strategic contexts, see Fischbacher et al. (2001) and Fischbacher and Gächter (forthcoming).

${ }^{5}$ Rawls points out that ' $\ldots$ undeserved inequalities call for redress; and since inequalities of birth and natural endowment are undeserved, these inequalities are to be somehow compensated for' (Rawls 1971, p. 100).
} 


\section{Results}

In this section, we first draw a general picture of the data (Sect. 4.1). These data show that participants' allocation choices mainly concentrate on several well-defined allocation rules. Next, we study the probability of rule choice across all our manipulations (Sect. 4.2). Finally, the main results of the experiment are summarized (Sect. 4.3).

\subsection{Different allocation rules and their frequency}

In contrast to the behavior we predicted for a selfish risk neutral subject we find well-defined behavioral patterns when information about the identities is not given. Those patterns include behavior that is compensating for initial inequalities, as well as patterns that are not doing so. We find that most subjects knowing their identity condition on it and act rather selfish. Nevertheless, some subjects still compensate for initial differences. Finally, we find behavioral differences regarding the type of good when information about identities is given. Those results will be presented in more detail in the following. In doing so we will distinguish between two main categories of allocation rules. The first category, the impartial rules, expresses subjects preferences over payoff distributions when being selfish is not possible, i.e. when identities are unknown. The partial rules, as a second category, include all those rules that are mainly driven by self-interest, i.e. can only be chosen when subjects know their identities.

Starting with treatments where subjects do not have information about identities, we find, as expected, a strongly significant relation between deciding behind the veil of ignorance and choosing an impartial rule (Mann-Whitney two-sample rank-sum test: $z=-4.134, p<0.001$, comparing $T^{10}$ and $T^{11} ; z=-5.892, p<0.001$, comparing $T^{00}$ and $T^{01} ; z=-2.613, p=0.009$, comparing $T^{10}$ and $T^{11}$; and $z=-5.684, p<0.001$, comparing $T^{00}$ and $\left.T^{01}\right){ }^{6}$ We find that the majority of the subjects $(72.22 \%)$, when not knowing their identity, choose an allocation vector coinciding with one of the following three impartial allocation rules. Under Full redress $(F R)$ subjects divide the pie such that initial inequalities are fully compensated for and each member of the group ends up having the same final payoff, resp. the same amount of lottery tickets, i.e. $\pi_{i}=(60,60,60)$. Under No redress $(N R)$, subjects divide the pie equally, such that the initial inequalities among the subjects are maintained in the final payoff structure, i.e. $\pi_{i}=(40,60,80)$. Under Half redress $(H R)$ subjects divide the pie such that unequal initial endowments are only partially compensated for and the initial inequalities among the three subjects are reduced by half. The final payoffs, resp. the amount of lottery tickets, therefore differ by ten units, i.e. $\pi_{i}=(50,60,70)$ (see Table 2 for an overview of the frequency of the allocation rules chosen).

When subjects have information about their identities, the majority of them acts partially $(56.67 \%)$. Across these treatments we identify two partial rules. Pure selfishness $(P S)$ captures choices where the subject allocates the whole pie to herself.

\footnotetext{
${ }^{6}$ The first two tests correspond to the small pie's condition and the two last results to the large pie's condition. To assess the impact of our two main treatments, we do not consider sessions where initial inequalities are asymmetric. This makes the results fully comparable.
} 
Table 2 Relative frequency of allocation rules

\begin{tabular}{lccccccc}
\hline Treatment & Obs. & FR $(\%)$ & NR $(\%)$ & HR $(\%)$ & PS $(\%)$ & CH $(\%)$ & Others $(\%)$ \\
\hline$T^{00}$ VOI - Indivisible $(P=60)$ & 30 & 53.33 & 30.00 & 3.33 & - & - & 13.33 \\
$T^{10}$ VOI - Divisible $(P=60)$ & 30 & 33.33 & 26.67 & 23.33 & - & - & 16.67 \\
$T^{01}$ No VOI - Indivisible $(P=60)$ & 30 & 6.67 & 3.33 & 0 & 46.67 & 40.00 & 3.33 \\
$T^{11}$ No VOI - Divisible $(P=60)$ & 30 & 13.33 & 6.67 & 10.00 & 30.00 & 30.00 & 10.00 \\
$T^{00}$ VOI - Indivisible $(P=180)$ & 30 & 46.67 & 26.67 & 6.67 & - & - & 20.00 \\
$T^{10}$ VOI - Divisible $(P=180)$ & 30 & 56.67 & 6.67 & 13.33 & - & - & 23.33 \\
$T^{01}$ No VOI - Indivisible $(P=180)$ & 30 & 6.67 & 0 & 0 & 20.00 & 30.00 & 43.33 \\
$T^{11}$ No VOI - Divisible $(P=180)$ & 30 & 43.33 & 0 & 0 & 6.67 & 23.33 & 26.67 \\
$T^{10}$ VOI - Divisible $(P=180)$, & 30 & 26.67 & 26.67 & 0 & - & - & 46.67 \\
asymm. 1) & & & & & & & \\
$T^{10}$ VOI - Divisible $(P=180)$, & 30 & 23.33 & 30.00 & 0 & - & - & 46.67 \\
asymm. 2) & & & & & & &
\end{tabular}

Note: FR: Full Redress, NR: No Redress, HR: Half Redress, PS: Pure Selfishness, CH: Charity

Charity $(\mathrm{CH})$ describes allocation vectors where the subject claims at least two thirds of the pie for herself and divide the rest among the other two subjects.

However, a non-negligible proportion of subjects $(22.5 \%)$ uses one of the three above defined impartial rules even when they know their identities. And they do so significantly more when distributing a divisible good than when distributing probabilities to get an indivisible good (Mann-Whitney two-sample rank-sum test: $z=-1.920, p=0.054$, when the pie is small; $z=-3.252, p=0.001$, when the pie is large). When identities are known one could expect behavioral differences to be dependent on the identity $i \in\{A, B, C\}$ of the group members. However, we do not find significant differences concerning the use of impartial rules that would confirm such an intuition. ${ }^{7}$

Finally, we consider our two robustness checks, the pie size and the symmetry of the initial endowments. We find that an increase in pie size leads to a dramatic decrease in partial behavior (Mann-Whitney two-sample rank-sum test: $z=3.027$, $p=0.002$, when the good is indivisible; $z=2.316, p=0.020$, when the good is divisible). In treatments with asymmetric initial inequalities between identities, more than half of the subjects apply an impartial allocation rule. However, in contrast to the corresponding original treatments where subjects did not know their identity, here no subject chose an allocation vector exactly coinciding with $H R$. Therefore, we rule out $H R$ as a stable pattern of behavior in the type of distribution problem at hand.

\footnotetext{
${ }^{7}$ To study (im)partial behavior by role, we pool the data from all the sessions where roles are known. In these sessions, $22.5 \%$ of participants $A$ choose an impartial rule, while $65 \%$ choose a partial rule; $20 \%$ of participants $B$ choose an impartial rule, while $55 \%$ choose a partial rule; $25 \%$ of participants $C$ choose an impartial rule, while $50 \%$ choose a partial one. Binary comparisons of the proportion of subjects choosing an (im)partial rule show that there are no differences between roles. We will study more formally this fact in the next subsection.
} 
Furthermore, we do not find statistical differences between the two asymmetric treatments.

\subsection{Dependence of rule frequency pooling all data}

We now concentrate on the impact of our different manipulations, including the robustness checks, on the frequency of both, partial and impartial rules. We use a multinomial logit model, pooling the data from all treatments. Our dependent variable has three categories: choices coinciding with an impartial rule $(n=157)$, choices coinciding with a partial rule $(n=68)$ and unclassified choices $(n=75)$. We use this latter category as the base outcome for comparison. We estimate the impact on the probability of choosing one of these three categories of our different treatment manipulations. To study the possibility of subjects conditioning behavior on their own role, we follow a procedure similar to Beckman et al. (2002). We introduce three information variables. First, Veil of ignorance takes the value 1 when participants act behind a veil of ignorance, i.e. do not know their identity, and 0 when they know. Second, Info $x A$ and Info $x C$ represent the interaction effects between information about the identities and the three roles. Each of these variables takes the value 1 when information is known and the subject has been assigned the role specified in the dummy, 0 otherwise. ${ }^{8}$ We furthermore include four other dummy variables in the model. Divisibility takes the value 1 when the good is divisible, 0 when it is indivisible. Large pie takes the value 1 when the pie is large $(P=180), 0$ when it is small $(P=60)$. Symmetry takes the value 1 when initial differences are symmetric, i.e. $\left(e_{B}-e_{A}\right)=\left(e_{C}-e_{B}\right)$, 0 otherwise. Finally, we control for the interaction effect between not knowing one's own identity (choosing behind the veil) and the divisibility of the good as we found some interesting interaction effects in the descriptive analysis. VOI $x$ DIV takes the value 1 when participants decide behind the veil of ignorance and the good is divisible, 0 otherwise.

As shown in Table 3, the probability of choosing an impartial rule increases with both, not having information about identities and the divisibility of the good. Moreover, we find a crowding-out effect between the divisibility of the good and the information about the identities. Although both variables have a positive impact on impartiality, their interaction effect is negative. Thus, the combined effect is less than the sum of the independent effects. The impact of divisibility on partial rules is not significant. The symmetry of initial inequalities also increases the probability of choosing an impartial rule. On the other hand, when subjects distribute a large pie $(P=180)$, the probability of choosing a partial rule is significantly smaller.

Subjects do not condition on their own identity in the game when proposing a distribution. This is shown by the fact that the two identity dummies are not significant. This means that choosing an allocation coinciding with a(n) (im)partial rule is mainly driven by knowing/not knowing the own identity and not by the relative position of this identity. In this sense, we do not find support for the kind of 'positional bias' described in Beckman et al. (2002).

\footnotetext{
${ }^{8}$ The interaction between having information and being player B (Info $x B$ ) is the base outcome for comparison and hence it is not included in the model.
} 
Table 3 Multinomial logit estimates of effects of treatment variables

\begin{tabular}{|c|c|c|c|c|}
\hline & \multicolumn{2}{|l|}{$\underline{\text { Partial rules }}$} & \multicolumn{2}{|c|}{ Impartial rules } \\
\hline & Coef. & Std. Err. & Coef. & Std. Err. \\
\hline Veil of Ignorance & -36.056 & $1.17 \mathrm{e}+07$ & 2.829 & $0.756^{* * *}$ \\
\hline Info $x A$ & 0.956 & 0.656 & 0.857 & 0.759 \\
\hline Info $x C$ & -0.128 & 0.586 & 0.248 & 0.682 \\
\hline Divisibility & -0.300 & 0.517 & 1.682 & $0.645^{* *}$ \\
\hline Large pie & -1.964 & $0.477^{* * *}$ & -0.782 & $0.392^{*}$ \\
\hline Symmetry & -0.189 & 0.574 & 0.907 & $0.442^{*}$ \\
\hline \multirow[t]{3}{*}{ VOI $x$ DIV } & 0.134 & $1.44 \mathrm{e}+07$ & -1.911 & $0.803^{*}$ \\
\hline & log likelihood & -197.985 & Prob $>\chi_{2}$ & 0.0000 \\
\hline & observations & 300 & Pseudo $R^{2}$ & 0.3542 \\
\hline
\end{tabular}

*** $p<0.001{ }^{* *} p<0.01{ }^{*} p<0.05$

Note: The dependent variable has three categories: choices coinciding with an impartial rule $(n=157)$, choices coinciding with a partial rule $(n=68)$ and unclassified choices $(n=75)$ as the base outcome for comparison.

\subsection{Summary of the results}

In a three-person pure distribution problem with arbitrarily unequal initial endowments where subjects either know or do not know their endowment, our findings are as follows:

Result 1: When identities are unknown the majority of the subjects (72\%) choose among three impartial rules: Full Redress, Half Redress, No Redress.

Result 2: When identities are known a non-negligible proportion of subjects $(22.5 \%)$ still choose one of the three impartial rules.

Result 3: Subjects' overall impartial behavior is affected by the type of good. When distributing probabilities to get an indivisible good, impartial rules are used less frequently.

Result 4: When the size of the additional pie to be distributed is tripled, partial behavior decreases dramatically.

\section{Discussion}

Much of the recent economic experimental literature on distributive justice has focused on how merit and entitlements discourage egalitarian behavior in simple distribution and bargaining games. In contrast, we have studied the extent to which the arbitrary origin of initial inequalities produces egalitarian responses under certain conditions. Our results are in line with previous results on the multiplicity of fairness rules (see Frohlich and Oppenheimer 1992; Konow 2000; Frohlich et al. 2004; 
Cappelen et al. 2007). Moreover, given the arbitrary nature of initial inequalities in our experiment, we discover a new set of compensation rules that resemble Rawls' 'principle of redress' (Rawls 1971).

Our first treatment manipulation, (no) information about identities, creates a condition for impartiality. This argument is consistent with several theories of justice, such as those by Rawls (1971), Harsanyi (1975), and Gauthier (1986). We claim that decisions made without having information about identities, i.e. behind a veil of ignorance, reflect first, impartial preferences and second, given the arbitrary nature of endowments, that those impartial preferences are mostly inspired by the "principle of redress'. Since the arbitrariness of endowments is maintained in all treatments, we further claim to find this principle when information about identities is provided, i.e. the veil of ignorance is lifted. However, these claims are subject to a restriction. The redressing behavior we find without information about identities could possibly be motivated by risk aversion as well. Due to our experimental design we cannot disentangle between those two explanations. Nevertheless, an analysis of subjects' behavior with information about identities and the proportion of risk aversion in the population, enables us to qualify this restriction to some extent. When subjects know their identity their behavior is similar to the behavior found in treatments where they do not know their identity. In other words, the same behavioral rules apply for both cases. When identities are known, in contrast to when they are unknown, risk aversion does not hold as an explanation. Due to the arbitrariness of endowments in both cases we are prone to say that these decisions are at least partly motivated by the same reason. Moreover, the share of redressing behavior we find when identities are known amounts to $40 \%$ (considering only full redress). Although there is a slight tendency towards risk aversion in the population, this tendency is not sufficient to explain behavior when identities are unknown. ${ }^{9}$ Thus, although we cannot unequivocally say that the rules we elicited are genuinely impartial, we are firm to say that impartiality is a possible behavioral motive behind the systematic deviations from the economically anticipated self-interest in the context of arbitrary endowments.

Another finding that we would like to discuss here is related to our type-of-good manipulation. Overall, a significantly higher number of subjects distribute according to an impartial rule when the good is divisible rather than indivisible. In other words, the mere fact that subjects can influence a procedure, via distributing lottery tickets, rather than a pure outcome, reduces impartial behavior. However, this effect is stronger in the treatments where subjects have information about their identities. ${ }^{10}$ Possibly, one could relate this finding to the uncertainty that subjects face concerning the moral outcome of their decision in the indivisible good treatments. Distributing lottery tickets creates a sort of 'moral wiggle room' (Cappelen et al. 2007) as it is not

\footnotetext{
${ }^{9}$ In a recent study of survey and experimental data on general risk preferences in the German population Dohmen et al. (forthcoming) find that on a scale of 0 to 10 , where 0 indicates a complete unwillingness to take risk, the modal response is 5. There is substantial fraction of subjects' answers between 2 and 8 , but there is also a fraction of $7 \%$ stating 0 .

${ }^{10}$ Since knowing the identity triggers selfish behavior one could expect that the reversed argument, that divisibility affects selfish behavior, is true as well. We do not find a significant impact of divisibility on selfish behavior. This supports the above conclusion that risk aversion plays only a minor role here even further (as referred to also in footnote 3).
} 
clear what the final allocation will be. In contrast the allocation of the divisible good leaves no doubt on the (un)fairness of outcomes. ${ }^{11}$

We consider our findings to be surprising and therefore deserving of further empirical investigation. We firmly believe that the study of impartial preferences in experimental distribution and bargaining situations is a promising line of research that can shed much light upon important behavioral patterns we observe in many experimental studies as well as in daily life. Given that principles of redress and compensation underlie important public interventions, e.g. affirmative action and positive discrimination policies, we could benefit from a better understanding of how these principles work and of the institutional features that foster them.

Acknowledgements We are grateful to the editor and two referees for constructive advice that induced major revisions of the article. We also thank Fernando Aguiar, Raymond Duch, Werner Güth, Glenn Harrison, Oliver Kirchkamp, Vittoria Levati, Birendra Kumar Rai and various conference, workshop and seminar participants for their helpful comments on earlier versions of this paper. Luis M. Miller acknowledges the financial support received from the Spanish Ministry of Education (SEJ2006-00959/SOCI).

Open Access This article is distributed under the terms of the Creative Commons Attribution Noncommercial License which permits any noncommercial use, distribution, and reproduction in any medium, provided the original author(s) and source are credited.

\section{References}

Beckman, S. R., Formby, J. P., Smith, W. J., \& Zheng, B. (2002). Envy, Malice and Pareto efficiency: An experimental examination. Social Choice and Welfare, 19, 349-367.

Berg, J. E., Daley, L. A., Dickhaut, J. W., \& O’Brien, J. R. (1986). Controlling risk preferences for lotteries on units of experimental exchange. Quarterly Journal of Economics, 101(2), 281-306.

Bolton, G. E., \& Ockenfels, A. (2000). ERC: A theory of equity, reciprocity, and competition. American Economic Review, 90(1), 166-193.

Bolton, G. E., Brandts, J., \& Ockenfels, A. (2005). Fair procedures: evidence from games involving lotteries. The Economic Journal, 115(506), 1054-1076.

Camerer, C. (2003). Behavioral game theory. Princeton: Princeton University Press.

Cappelen, A. W., Hole, A. D., Sorensen, E. O., \& Tungodden, B. (2007). The pluralism of fairness ideals: an experimental approach. American Economic Review, 97(3), 818-827.

Cherry, T. L., Frykblom, P., \& Shogren, J. F. (2002). Hardnose the dictator. American Economic Review, 92(4), 1218-1221.

Cox, J. C., Roberson, B., \& Smith, V. L. (1982). Theory and behavior of single unit auctions. In V. L. Smith (Ed.). Research in experimental economics (Vol. 2 pp. 1-43). Greenwich: JAI.

Dohmen, T., Falk, A., Huffman, D., Sunde, U., Schupp, J., \& Wagner, G. G. (forthcoming). Individual risk attitudes: New evidence from a large, representative, experimentally-validated survey. Journal of the European Economic Association.

Fehr, E., \& Schmidt, K. M. (1999). A theory of fairness, competition, and cooperation. The Quarterly Journal of Economics, 114(3), 817-868.

Fischbacher, U. (2007). Zurich toolbox for readymade economic experiments. Experimental Economics, 10(2), 171-178.

Fischbacher, U., \& Gächter, S. (forthcoming). Social preferences beliefs, and the dynamics of free riding in public good experiments. American Economics Review.

Fischbacher, U., Gächter, S., \& Fehr, E. (2001). Are people conditionally cooperative? Evidence from a public goods experiment. Economics Letters, 71, 397-404.

\footnotetext{
${ }^{11}$ We thank an anonymous referee for pointing this out to us. For recent studies on 'procedural fairness', see Bolton et al. (2005); Karni et al. (2007); and Krawczyk (2007).
} 
Frohlich, N., \& Oppenheimer, J. A. (1992). Choosing justice. An experimental approach to ethical theory. Los Angeles: University of California Press.

Frohlich, N., Oppenheimer, J. A., \& Kurki, A. (2004). Modeling other-regarding preferences and an experimental test. Public Choice, 119, 91-117.

Gauthier, D. (1986). Morals by agreement. Oxford: Clarendon.

Greiner, B. (2004). An online recruitment system for economic experiments. In K. Kremer \& V. Macho. Forschung und wissenschaftliches Rechnen (pp. 79-93). GWDG Bericht 63. Ges. für Wiss. Datenverarbeitung, Göttingen.

Harsanyi, J. (1975). Can the maximin principle serve as a basis for morality? American Political Science Review, 69, 599-606.

Karni, E., Salmon, T., \& Sopher, B. (2008). Individual sense of fairness: an experimental study. Experimental Economics, 11(2), 174-189.

Konow, J. (2000). Fair shares and cognitive dissonance in allocation decisions. American Economic Review, 90(4), 1072-1091.

Konow, J. (2003). Which is the fairest one of all? A positive analysis of justice theories. Journal of Economic Literature, 41(4), 1188-1239.

Krawczyk, M. (2007). A glimpse through the veil of ignorance: equality of opportunity and support for redistribution. Mimeo.

Rawls, J. (1971). A theory of justice. Cambridge: Harvard University Press.

Rutström, E. E., \& Williams, M. B. (2000). Entitlements and fairness: an experimental study of distributive preferences. Journal of Economic Behavior and Organization, 43(1), 75-89.

Roth, A. E., \& Malouf, M. W. K. (1979). Game-theoretic models and the role of information in bargaining. Psychological Review, 86, 574-594.

Young, H. P. (1994). Equity in theory and practice. Princeton: Princeton University Press. 